\title{
Comparing negative emissions and high renewable scenarios for the European power system
}

\author{
F. Gaffney ${ }^{1,2^{*}}$, J. P. Deane ${ }^{1,2}$, G. Drayton ${ }^{3}$, J. Glynn $n^{1,2}$ and B. P. Ó. Gallachóir ${ }^{1,2}$
}

\begin{abstract}
Emerging literature highlights the essential role played by decarbonised electricity generation in future energy systems consistent with the Paris Climate Agreement. This analysis compares the impacts of high levels of renewable electricity and negative emissions technologies on exploratory visions of the future EU power system (2050) in terms of emissions reduction, technical operation and total system costs. The analysis shows that high renewable power system scenarios coupled with low levels of negative emissions technologies, such as biomass carbon capture and storage ( $<2 \%$ of installed capacity), can deliver a net-negative European power system at lower comparable cost without breaching published sustainable biomass potentials in Europe (or requiring imports) or geological storage potentials while also contributing to power system inertia. Direct air capture has the capability to further decrease overall carbon emissions. While carbon capture and storage and power-to-gas must overcome market, regulatory and social acceptance challenges, given their potential benefits to emissions reduction, costs and system operation their role in a future power system should be further explored.
\end{abstract}

Keywords: Deep decarbonisation, Negative emissions power systems, Carbon capture and storage, Direct air capture, Paris climate agreement

\section{Introduction}

Decarbonising electricity generation is a key element in achieving the Paris Climate Agreement [1] for limiting average global temperature rise to 'well below $2^{\circ} \mathrm{C}$ ' above pre-industrial levels. Multiple analyses involving varied levels of effort, technological development and policy support have explored the roles of high levels of renewable electricity, low carbon power, increased energy efficiency, and carbon capture and storage (CCS) on power system decarbonisation in Europe. However, the ratification of the Paris agreement demands a radical decarbonisation of the energy system [2] and may require certain

\footnotetext{
* Correspondence: fiac.gaffney@ucc.ie

'MaREl Centre, Environmental Research Institute, University College Cork, Cork, Ireland

${ }^{2}$ School of Engineering, University College Cork, Cork, Ireland

Full list of author information is available at the end of the article
}

sectors within the economy to achieve net negative emissions [3]. Furthermore, a recent report by the Intergovernmental Panel on Climate Change [4] highlights the importance of carbon dioxide removal and net negative emissions to achieving the goals of the Paris Climate Agreement. Combining bioenergy with carbon capture and storage technology (BECCS) and/or the use of direct air capture (DAC) offers the prospect of electricity supply with large-scale net negative emissions [2]. There are challenges and risks associated with both CCS and DAC technologies around the availability and provision of the biomass required for BECCS, the storage of $\mathrm{CO}_{2}$ and the financing of such plants.

There is a gap in the literature in that detailed highresolution (sub-hourly) power system analysis comparing decarbonisation pathways is lacking. Studies to date fail to adequately address the short-term operational challenges 
associated with incorporating high penetration levels of non-synchronous variable energy resources. Jacobson, Delucchi [5], for example, match averaged energy supply and demand for 20 world regions on a per annum basis. Pursiheimo, Holttinen [6] use time slices to analyse the effects of high renewable energy shares in the global energy system. Both examples identify the lack of high temporal resolution modelling as potential weaknesses in their methodologies; a view closely aligned with key findings from Bogdanov, Farfan [7] when analysing transition pathways to sustainable global energy systems. Other publications with a more Europe-centric focus, such as $[8,9]$, also tend to overlook the value added through sub-hourly resolution modelling. The concept of using typical sample days or representative time slices to provide a robust analysis of power (or energy) systems may have become outdated with the advent of variable generation resources representing a significant share of future systems. The inability to account for energy transfer between sequential horizon timeframes directly results in a misrepresentation and an underestimation of the value added from system flexibility and energy storage technologies, in particular. Flexibility and storage are two key elements associated with facilitating variable generation in reliable power systems. Much analysis has been undertaken on understanding high variable renewable futures, the roles of flexibility [10] and storage [11] within those different pathways along with the economics [12]. Less analysis has focused on comparing these high variable renewable futures with negative emission power system scenarios.

In this article we use a power system model with high temporal and high technical resolution to investigate three near-optimal scenarios in terms of emissions reduction, technical operation and system costs for the year 2050. The use of cost optimal long term expansion tools to develop scenarios assumes rational behaviour and market equilibrium in future power system, however Trutnevyte [13] shows that cost optimization may not approximate the real-world transition while nearoptimal scenarios can encapsulate the real-world transition. The scenarios represent a counterfactual along with two climate mitigation pathways: one dependent on high levels of variable generation and the other reliant on negative emissions technologies (NETs). These exploratory scenarios, with varying portfolios, meet the same electricity demand and use the same fuel price assumptions. This allows for direct comparative analysis and are not proposed to be optimal portfolios. Furthermore, this analysis limits both the bioenergy resource availability [14] and geological storage potential of $\mathrm{CO}_{2}$ [15-17] to within published potentials for Europe.

The novelty in this work surrounds the modelling of the European power system and the added value achieved in doing so. Firstly, the dependencies between the system adequacy of each scenario and the reliance on weather-dependent power generation is assessed by applying a multi-sample methodology that incorporates 30 individual weather profiles for wind and solar power generation based on the previous three decades. This is followed by in depth analyses simulated at 5-min temporal resolution to gain new insights into the technical limitations of operating a large power system under the conditions of each scenario. Modelling with aggregated typical operational periods as time slices was not considered here as the approach fails to represent energy exchange which is an essential part of a functioning power system with high levels of variable renewable energies; a standpoint in agreement with Kotzur, Markewitz [18]. The end result of high temporal modelling is an appreciation for a power system's ability (or inability) to facilitate variable generation from wind and solar energy sources which can dictate the level of decarbonisation achieved.

In an effort to promote transparent, reproducible science the PLEXOS European model used in this work along with all associated data will be made available on request for academic research. The recent, well publicised, controversy between Jacobson, Delucchi [19] and Clack, Qvist [20] and their divergent views regarding a fully decarbonised U.S. energy system highlight the importance of transparency regarding assumptions used to determine the feasibility (or viability) of such scenarios. Yet, as Pfenninger [21] points out, energy research lags behind other scientific fields such as medicine or economics [22, 23] in moving to more open and reproducible science [24]. The realisation that this research field is directly relevant to the urgent policy challenge of rapid energy system decarbonisation makes reproducibility of results particularly important $[25,26]$.

\section{Results and discussion}

This analysis will provide insights into several decarbonisation pathways for Europe. In doing so, the focus is on the facilitation of carbon-neutral generation, the impact of NETs on system carbon intensity, operational characteristics of the power system and the challenges associated with changing portfolios and finally, the economics.

\section{Decarbonisation scenarios}

Decarbonisation portfolios and scenarios are developed using exploratory pathways stemming from the European Commission and the International Energy Agency. Primarily based on technology, cost and demand projections the European Commission's 'EU Reference Scenario 2016' [27] report provided the basis for the counterfactual scenario. Another publication from the European Commission, the 'Energy Roadmap 2050' [28] report, provided 
inspiration for the 'High VRE' scenario and finally, the International Energy Agency's 'Energy Technology Perspectives 2017' report [29], specifically the Beyond $2{ }^{\circ} \mathrm{C}$ scenario, was the foundation from which the 'Negative Emissions' scenario was created. Hereafter, the scenarios are simply referred to as 'Reference', 'High VRE' and 'Negative Emissions' respectively. The main distinguishing factors between mitigation scenarios are as follows:

- the High VRE scenario relies heavily on enabling technologies such as power-to-gas and interconnection to facilitate the high share of VRE generation capacity;

- the Negative Emissions scenario is centred around low carbon energy (i.e. nuclear) along with biomass fitted with carbon capture technology. An overview of the scenarios is shown in Fig. 1.

\section{Energy mix and the effect of weather-dependent power generation}

The analysis begins with an assessment of the overall energy mix for each scenario while accounting for interannual variability inherently present in certain power generation sources. It was decided to include a multi-sample methodology, akin to an approach used by Collins, Deane [30] where 30 individual wind and solar profiles are simulated in parallel, to assess the dependency/exposure to inter-annual variability associated with variable generation in each scenario. From viewing the results depicted in Fig. 2, clear parallels can be drawn between scenarios and their individual dependencies on difference generation classes. The figure also reveals that while variable RE is inherently unpredictable in nature, both dispatchable RE and low carbon generation classes facilitate/complement this unpredictability across the samples to reduce the overall volatility of non-fossil fuel generation share, specifically in the climate mitigation scnearios.

\section{Sector decarbonisation}

Energy mix categories are presented in Table 1 to highlight their respective share. While uncertainty exists around the role for nuclear power in future decarbonisation scenarios, Table 1 shows that without this form of low carbon energy both the Reference and Negative Emissions scenarios remain far from decarbonised at 51.5 and $74.8 \%$ respectively. On the other hand, the High VRE scenario is almost fossil fuel-free. This is, in part, due to the influence of hydrogen, created via power-to-gas, displacing natural gas; thereby providing

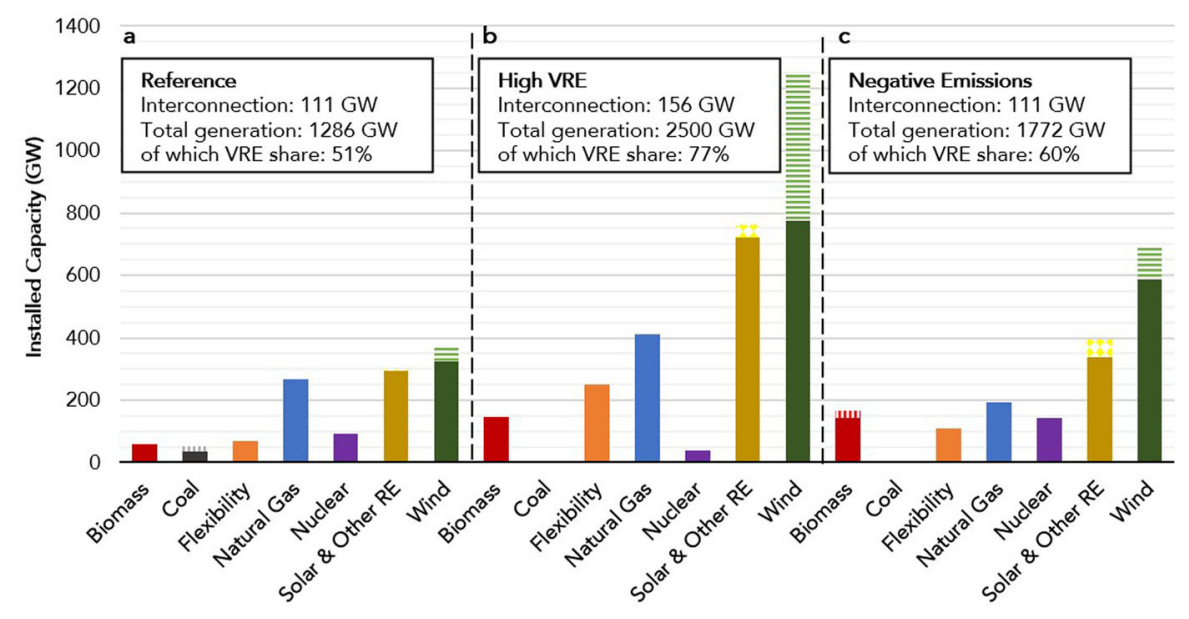

\begin{tabular}{|c|c|c|c|c|c|c|c|c|}
\hline Lab & & $\begin{array}{r}\text { Fossil } \\
\text { Generat } \\
\mathrm{CC}\end{array}$ & with & $\begin{array}{c}\text { Negative } \\
\text { Emission } \\
\text { Technology }\end{array}$ & \multicolumn{3}{|c|}{ Enabling Technology } & $\begin{array}{l}\text { Variable } \\
\text { Generation }\end{array}$ \\
\hline $\begin{array}{c}\text { Core } \\
\text { Scenarios }\end{array}$ & Code & $\begin{array}{c}\text { Natural } \\
\text { Gas }\end{array}$ & Coal & BECCS & $\begin{array}{l}\text { Power- } \\
\text { to-gas }\end{array}$ & $\begin{array}{c}\text { High } \\
\text { Interconnection } \\
\text { Capacity }\end{array}$ & $\begin{array}{c}\text { Demand } \\
\text { Response \& } \\
\text { Battery }\end{array}$ & High VRE \\
\hline Reference & $R E F$ & $x$ & $x$ & & & & $x$ & \\
\hline High VRE & $H-V R E$ & $x$ & & & $x$ & $x$ & $x$ & $x$ \\
\hline $\begin{array}{l}\text { Negative } \\
\text { Emissions }\end{array}$ & $N E$ & & & $x$ & & & $x$ & \\
\hline
\end{tabular}

Fig. 1 Scenario overview for the EU-27 plus the United Kingdom. In a, b, c, patterned areas are associated with Biomass, Natural Gas and Coal indicate their respective CCS capacities. Patterned areas associated with Solar \& Other RE represents the Other RE within the stack, while the patterned area in the Wind stack represents Offshore Wind. $\mathbf{d}$, Presents an overview of the scenarios analysed in this article. The Reference scenario demand projections are applied across all scenarios with installed generation capacities adjusted linearly to ensure robust, direct comparative analysis can be drawn between each pathway. See Methods for further details 

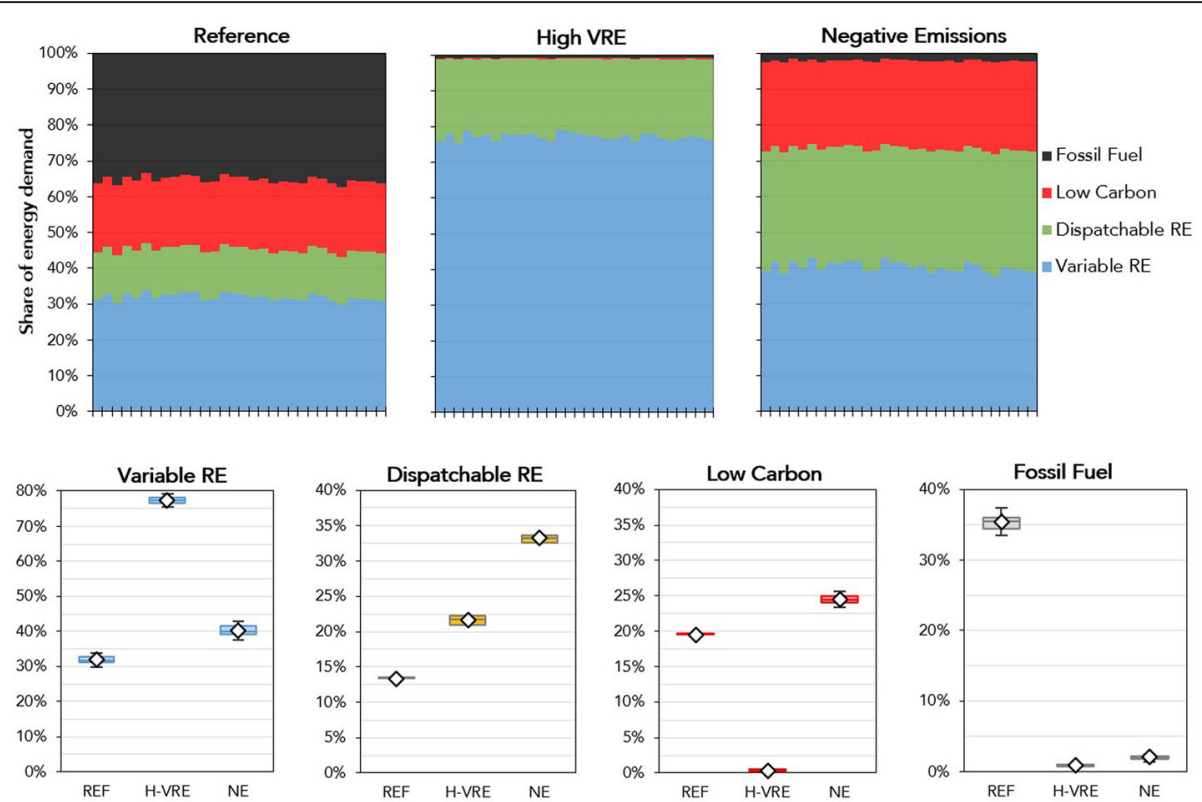

Fig. 2 High level insights into the energy mix of each scenario. Electricity generated from hydrogen in natural gas power plants is accounted for in the dispatchable RE category

a renewable yet dispatchable source of generation. For context, the fossil fuel generation share would increase from 1.5 to $4.5 \%$ without the presence of power-to-gas in the High VRE scenario.

\section{The role of flexibility}

System flexibility is essential for future power systems with high variable generation to operate robustly. This analysis incorporates flexibility through battery technology, pumped hydro capacity, power-to-gas and demand response. Further details are available from Methods.

In power systems with large dependencies on variable generation, it is well established that flexibility with short time constraints (hours) such as batteries and demand response has limited use outside of intra-day trading due to energy capacity technical limitations. This type of flexibility offers dependable flexibility for load-shifting across several hours. Pumped hydro storage may span days and even weeks but would not be economically feasible to be utilised for seasonal storage from the perspective of a grid operator/utility/et cetera. Power-to-gas (PtG) on the other hand, offers a seasonal energy storage

Table 1 Generation shares by category and scenario

\begin{tabular}{llll}
\hline Category & Reference & High VRE & Negative Emissions \\
\hline Variable Renewable Energy & $28.0 \%$ & $71.7 \%$ & $45.2 \%$ \\
Renewable Energy & $51.5 \%$ & $93.7 \%$ & $74.8 \%$ \\
Low Carbon & $68.7 \%$ & $98.5 \%$ & $96.0 \%$ \\
Fossil Fuel & $31.3 \%$ & $1.5 \%$ & $4.0 \%$ \\
\hline
\end{tabular}

option that other climate mitigation scenarios with large scale variable renewable energies often lack. With PtG, otherwise curtailable energy can be converted into a storable gas or liquid form to be utilised at will. In this analysis, excess power is converted to hydrogen which substitutes natural gas directly and can be used for power generation in combined cycle (or open cycle) gas turbines, i.e. providing renewable yet dispatchable power.

Table 2 summarises the average capacity factors of each source of flexibility. Between the options over short time periods, the table shows demand response, battery and then pumped hydro technologies being preferred in that order; a finding directly related to the efficiencies assumed (see Methods for more). It must be recognised that technologies, such as batteries, offer more to the power system than simple load-shifting which is all this analysis captures. The ability to provide ancillary services and voltage response for example, adds significant value to overall system operations, yet are not captured in this analysis.

Table 2 Capacity factors of the different flexibility options

\begin{tabular}{llll}
\hline Type & Reference & High VRE & $\begin{array}{l}\text { Negative } \\
\text { Emissions }\end{array}$ \\
\hline Demand Response & $38 \%$ & $27 \%$ & $32 \%$ \\
Pumped Hydro Energy Storage & $4 \%$ & $6 \%$ & $7 \%$ \\
Battery & $26 \%$ & $12 \%$ & $15 \%$ \\
Power-to-gas & N/A & $44 \%$ & N/A \\
\hline
\end{tabular}




\section{Biofuel resource and carbon storage}

Regional bioenergy resource potentials restricts the amount of woody biomass available to 5.2 EJ [14] (median estimate, equates to $2-5 \%$ of the estimated total sustainable bioenergy potential globally [31]) and no imports are assumed outside of the European Union. This compares to a value of $2.3 \mathrm{EJ}$ [27] used for power generation in 2015. This analysis does not consider any indirect land use change impacts or direct impacts. Limiting the regional biofuel resource potential did not result in a binding constraint in any scenario. Across the three scenarios, $40-72 \%$ of the potential was consumed however competition for this resource from areas outside of power system is not considered. This highlights a need for improved multi-sector cost optimization modelling while constructing decarbonisation scenarios as sustainable bioenergy may be better served in sectors that are traditionally more difficult to decarbonised, such as the transport sector for example. In this analysis, the negative emission scenario consumes the highest level of biomass (3.7 EJ). As abated and unabated biomass power generation is fundamental to IEA's 'Beyond $2^{\circ} \mathrm{C}$ scenario', upon which this scenario was inspired, it was decided to highlight this dependency rather than change the fundamentals of the scenario.

The transport and storage of captured carbon is limited in some countries, such as Austria, Cyprus, Estonia, Finland, Malta, Portugal and Sweden where geological capacity for storage is negligible [15-17]. Consequently, CCS capacity is not introduced in these Member States. Country-specific volumetric $\mathrm{CO}_{2}$ storage constraints sourced from Vangkilde-Pedersen, Anthonsen [15] and Lewis, Bentham [17] were included in the analysis. This did not result in a binding constraint in any scenario. For context; the largest regional storage required for the single year under investigation was 131 million tonnes compared to $117-360$ billion tonnes of storage estimated by Vangkilde-Pedersen, Anthonsen [15].

\section{Carbon intensity and the impact of NETs}

Figure 3 illustrates the gross $\mathrm{CO}_{2}$ production, the $\mathrm{CO}_{2}$ abatement and associated carbon intensity of each scenario. The Negative Emissions scenario achieves a $\mathrm{CO}_{2}$ intensity of $-19.4 \mathrm{kgCO}_{2} \mathrm{MWh}^{-1}$ (78.5 million tonnes of $\mathrm{CO}_{2}$ $\left(\mathrm{MtCO}_{2}\right)$ sequestered) compared to $-1.1 \mathrm{kgCO}_{2} \mathrm{MWh}^{-1}$ (4.6 $\mathrm{MtCO}_{2}$ sequestered) for the High VRE alternative across the year, 2050. Interestingly, the High VRE scenario achieves a net-negative status as hydrogen produced from otherwise curtailable renewable energy displaces natural gas consumed in power plants fitted with CCS, thereby acting as a means of producing net-negative carbon emissions.

With respect to the role NETs plays in each scenario, Fig. 3 identifies the carbon intensity achieved when no NETs are made available in the scenarios. In summary, the figure identifies 1) the system-wide $\mathrm{CO}_{2}$ intensity differential between scenarios, 2) the reliance of each scenario on negative emission technologies and 3) the role hydrogen can play in a decarbonisation pathway with extremely high levels of variable generation to achieve a net-negative power system.

\section{Is there potential to further decarbonise with direct air capture?}

Direct air capture (DAC) technology is a process where energy, usually power and thermal sources, is used to extract carbon dioxide directly from the atmosphere. DAC projects, such as Climeworks [32], have successfully been in commercial operation for several years. The technology is expected to play a role in energy sector decarbonisation, as highlighted by Realmonte, Drouet [33]. As such, DAC was included in the analysis as a means to

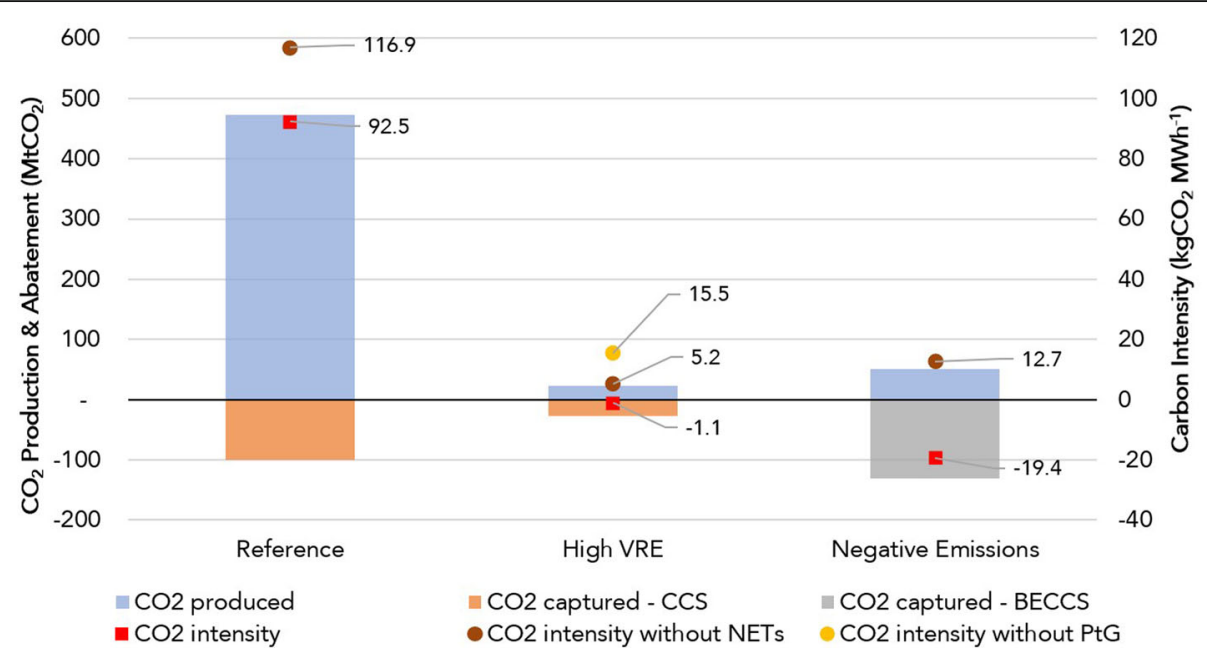

Fig. 3 Gross $\mathrm{CO}_{2}$ production, $\mathrm{CO}_{2}$ capture and carbon intensity for each scenario 
Table 3 An overview of the energy requirements, gross $\mathrm{CO}_{2}$ production increase, captured $\mathrm{CO}_{2}$ and $\mathrm{CO}_{2}$ intensities associated with using DAC for each of the main scenarios in 2050. System-wide $\mathrm{CO}_{2}$ intensity is shown without DAC first, then with DAC but excluding $\mathrm{CO}_{2}$ abatement from the technology because strictly speaking, it is not part of the power system. Finally, the $\mathrm{CO}_{2}$ intensity is illustrated with the abated emissions from DAC included

\begin{tabular}{|c|c|c|c|}
\hline & Reference & High VRE & Negative Emissions \\
\hline Electricity Requirement (TWh) & 2 & 225 & 151 \\
\hline Thermal Requirement (TWh) & 14 & 1362 & 916 \\
\hline Gross $\mathrm{CO}_{2}$ Production Increase (Mt) & 1 & -1 & -10 \\
\hline $\mathrm{CO}_{2}$ Capture Increase (Mt) & -13 & -1236 & -831 \\
\hline Carbon Intensity without $\mathrm{DAC}\left(\mathrm{kgCO}_{2} \mathrm{MWh}^{-1}\right)$ & 92.5 & -1.1 & -19.4 \\
\hline Carbon Intensity with DAC $\left(\mathrm{kgCO}_{2} \mathrm{MWh}^{-1}\right)$ & 94.9 & -1.1 & -21.3 \\
\hline Carbon Intensity incl. DAC $\mathrm{CO}_{2}$ Capture $\left(\mathrm{kgCO}_{2} \mathrm{MWh}^{-1}\right)$ & 91.7 & -270.7 & -219.0 \\
\hline
\end{tabular}

'further decarbonise' each scenario. The technology is represented in the model as a variable demand that can only purchase power from low carbon energy sources; biomass-fired power being the exception due to resource restrictions.

Table 3 provides a summary of the energy inputs and resulting $\mathrm{CO}_{2}$ sequestered from the inclusion of $\mathrm{DAC}$ across the three scenarios. Aligned with findings from Fasihi, Efimova [34], this analysis assumes DAC consumes $182 \mathrm{kWhe}$ per tonne of $\mathrm{CO}_{2}$ captured and low temperature energy requirements are met using waste heat available from a wide range of industrial sources, as alluded to by Connolly, Lund [35]. The table illustrates the significant net effect DAC could have on mitigation scenarios to further decarbonise where excess low carbon power exists.

Including DAC in an assessment of various decarbonisation scenarios produces some thought-provoking results and discussions. For example, is carbon sequestered from DAC attributable to the power sector? From a future system planning perspective, the presence of power-to-gas (and its ability to soak up low cost power to convert to hydrogen) may be chosen over DAC in a power system optimisation algorithm, as the former can further decarbonise the sector while the latter has no tangible benefits to the power sector if carbon credits are not accounted for therein. In short, DAC only increases demand in the power sector if those emissions are not captured in the power sector. To counter this argument in relation to our analysis, PtG is installed to a point where hydrogen (which must derive from low carbon power sources) has displaced sufficient levels of natural gas to ensure a carbonneutral power system. Remaining low-cost electricity is available for the DAC process.

\section{Operational conditions across different trajectories}

Figure 4a provides an overview of generation share and a projection of VRE curtailment. As expected, there is a clear correlation between curtailment and greater reliance on VRE generation. However, one can also identify the positive dependency on PtG technology and the effect of DAC to manage VRE curtailment. The figure shows low carbon generation (renewables plus nuclear power) representing the majority share in both climate mitigation scenarios. Lower fossil fuel-fired generation in the mitigation scenarios reduces Europe's fossil fuel import dependency, thereby alleviating ever-present security of supply concerns for the region. Compared to the counterfactual (70\%), fossil fuels represent just 13 and $20 \%$ of total fuel usage in the High VRE and Negative Emission scenario respectively.

For all generation classes represented in Fig. 4b, capacity factors are lower in mitigation scenarios compared to the counterfactual. While this trend would be expected with unabated generation, we see relatively low capacity factor for abated generation specifically natural gas-CCS at $29 \%$ while BECCS operates near full availability. This type of insight illustrates a key benefit of simulating scenarios at high temporal resolution and the ability to account for the tangible characteristics of a power system to attain a more realistic view of actual operation. Taking an alternative approach, such as that of Jacobson, Delucchi [5] where technology-specific averaged-annual power supply is assumed, offers little to resemble real life system operation.

The reduction in synchronous generation capacity from lower capacity factors of thermal capacity impacts on a system's kinetic energy level, otherwise known as 'inertia'; a necessary element for maintaining secure, reliable power through frequency stability [37]. Synchronous generators such as nuclear, coal, natural gas and biomass that contain mass mechanical components whose rotation is synchronised with the system frequency can provide system inertia. Inertia can be thought of as a 'glue' that keeps generating units synchronised in the power system, allowing the system to deal effectively with fast changes in frequency [38]. Batteries, demand response and fast frequency response technologies are, in theory, able to provide active power in very short (sub-second) timescales and can partially 

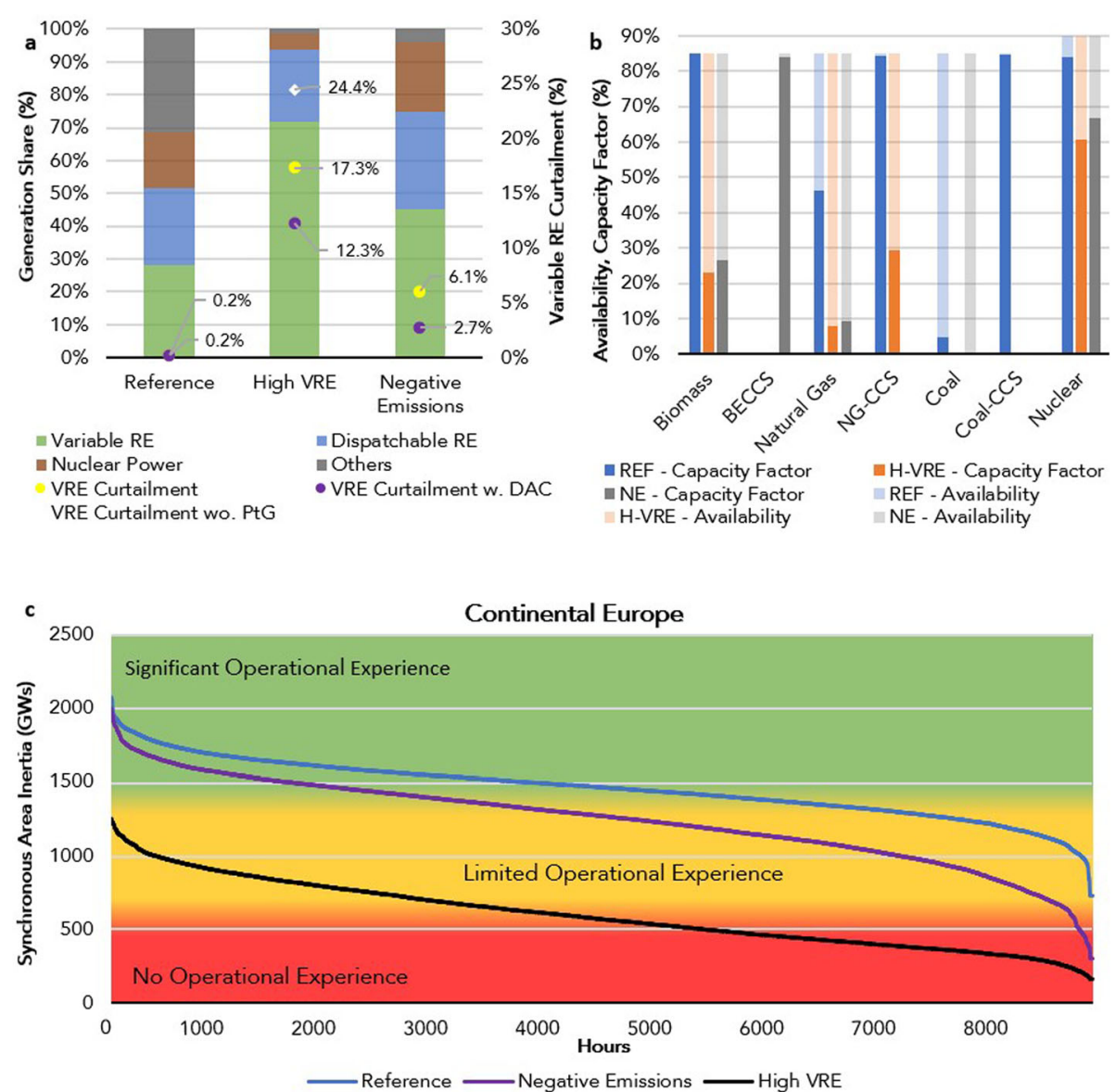

Fig. 4 Power generation characteristics for the EU-27 plus the United Kingdom. a, Represents the disaggregated total generation share and system-wide variable RE curtailment. $\mathbf{b}$, Represents the capacity factor and availability for a selection of generation classes. $\mathbf{c}$, Represents the inertia duration curve for Continental Europe synchronous area. Colour coded areas in c are approximations based on kinetic energy (inertia) data available on other similar, yet smaller systems [36]

substitute for mechanical inertia [39]. Furthermore, the behaviour of large electricity systems under very low levels of inertia, coupled with the volume of frequency response needed to stabilize a large power system is not well understood. Today it is not possible to say how these systems will operate. Figure 4c illustrates the inertia levels of the Continental European synchronous area for each scenario. The figure shows scenarios with heightened levels of variable generation capacity enduring lower inertia levels, thereby making system operation a more challenging task. Additionally, the significance for Continental Europe in terms of 'operational experience' under these specific inertial conditions is estimated.

Total system costs and the effect of carbon-related costs This analysis aligns its use of the term total system costs' with that of the European Commission [40], meaning that carbon-related costs are not accounted for in the calculation since they are not seen as an "extra cost" from a societal perspective. Total system costs are shown as annualised, undiscounted costs where CAPEX is dispersed over the technical lifetime of the technology and variable costs are included. Carbon-related costs will be shown separately, as is the case in Fig. $5 \mathrm{a}$. It must be noted that this analysis assumes issues highlighted by Zakkour, Kemper [41] regarding current GHG emission frameworks not fully facilitating negative emissions technologies are resolved, thereby making negative emissions tradable to other carbon-intensive sectors that fall under the European ETS. In summary, Fig. 5a illustrates that 1) the High VRE scenario is more expensive in terms of total system costs and also carbon-related costs that the Negative Emissions scenario, 2) the Negative Emission scenario is a lower cost option than the counterfactual scenario and 3) the relationship between CAPEX and OPEX cost components across the scenarios shows significant shifting towards a more capital-centric model in both mitigation scenarios.

When calculating an incremental cost that encapsulates the expense of generating electricity in each 

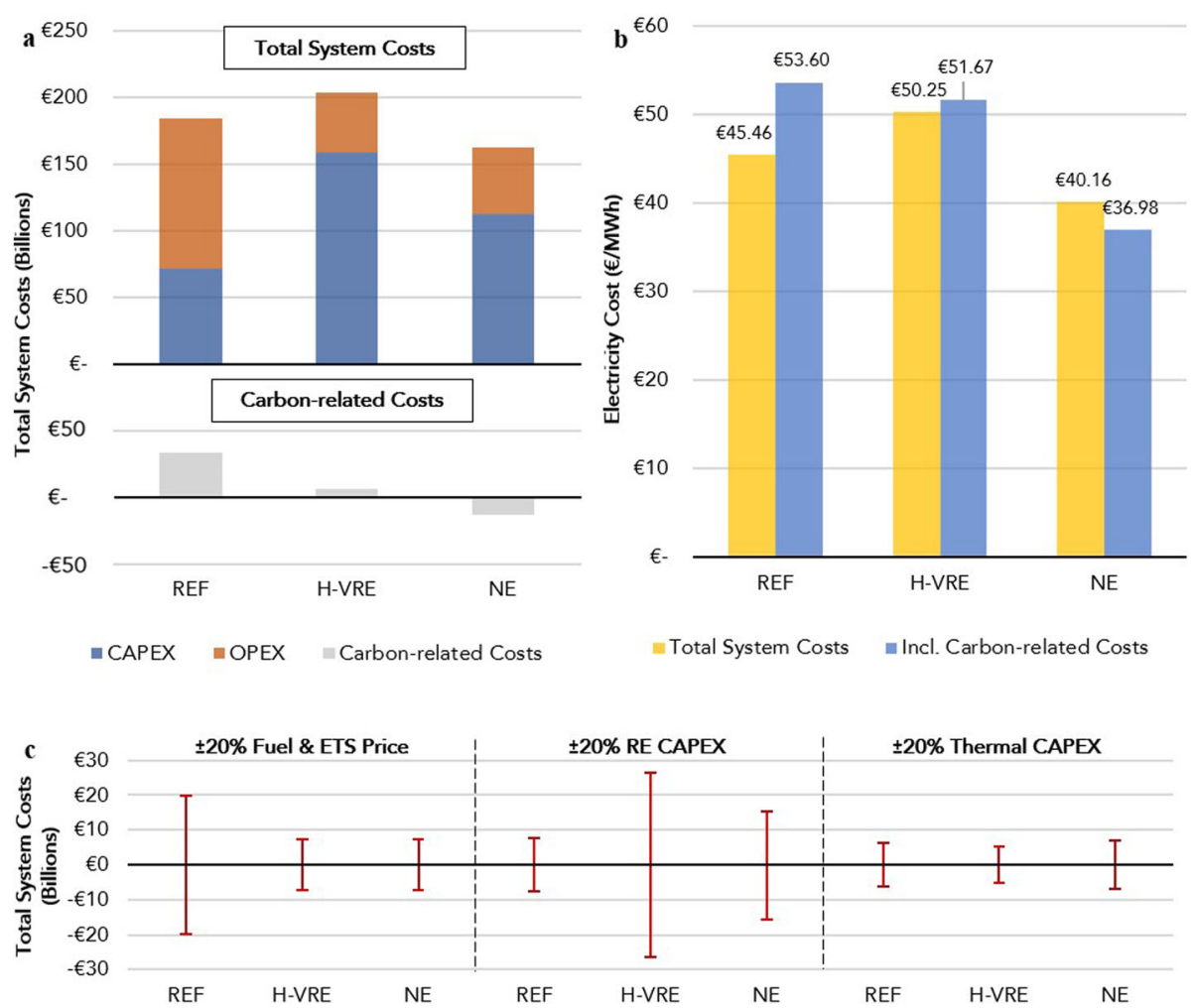

Fig. 5 Disaggregated total system costs and electricity costs. a, Represents disaggregated total system costs (top) and carbon-related costs (bottom). For further data on total system costs see Methods. $\mathbf{b}$, Represents the electricity cost per MWh delivered to the consumer across the year. These costs are effectively the total power system costs plus carbon-related costs relative to power consumed without any discounting included. c, Highlights total system cost change via error bars when applying a $\pm 20 \%$ cost sensitivity on various aspects of the system

scenario, carbon-related costs are included since, in practice, these are passed directly to the consumer, see Fig. 5b. While excluding taxes/levies, the electricity costs shown in the figure are represented with and without carbon-related costs to isolate and illustrate the effect on the end-user. It is interesting to view the difference carbon-related costs make on the incremental cost of electricity for each scenario shown. To explore this further, Fig. $5 \mathrm{c}$ reveals the change in total power system costs across the main scenarios when sensitivity analyses $( \pm 20 \%)$ are carried out on various cost elements of the power system.

\section{Conclusion}

This article shows that a High VRE scenario can achieve full decarbonisation $\left(-1.1 \mathrm{kgCO}_{2} \mathrm{MWh}^{-1}\right)$. It has also shown that a Negative Emissions scenario bound by regional biomass potentials and national $\mathrm{CO}_{2}$ storage potentials can achieve a power system-wide $\mathrm{CO}_{2}$ intensity reduction relative to the baseline scenario while remaining cost-comparable. Furthermore, converting less than $2 \%$ of the EU's installed generation capacity to BECCS consumes $72 \%$ of the projected available sustainable biomass while enabling the power system to achieve net-negative emissions (-19.4 $\left.\mathrm{kgCO}_{2} \mathrm{MWh}^{-1}\right)$ and maintaining the system inertia within operational experience of the system operators.

However, both technology readiness and technological choice play definitive roles in the results shown in this article. From a system decarbonisation perspective, the analysis showed that the state of readiness for CCS technology dictates whether the High VRE or Negative Emissions scenario achieves the lowest system-wide $\mathrm{CO}_{2}$ intensity. And finally, as a 'further step to decarbonisation', DAC technology was included to assess the potential benefits of the technology. The analysis showed that a positive $\mathrm{CO}_{2}$ capture to gross emissions ratio was achieved across the three main scenarios using DAC, therefore highlighting the potential for meaningful contributions to achieving a decarbonised power system (once captured $\mathrm{CO}_{2}$ is attributable to the power sector).

Notwithstanding the potential benefits of the abovementioned, risk exposures exist in several areas for NETs. Technology risk regarding the reliance on CCS coupled with questions over commercial readiness and scalability; operational risk where high concentrations of variable generation diminish generator capacity factors 
and system inertia levels; market participant risk with market prices reducing due to the overall shift in the cost of energy from operational costs to capital costs and finally; consumer risk with incremental electricity costs varying widely and therefore run the risk of heightening budgeting concerns for the consumer.

The benefit of high temporal resolution dispatch modelling demonstrates that 1) abated generation such as natural gas may not surpass $30 \%$ capacity factor in mitigation scenarios and 2) unabated biomass and natural gas generation endures capacity factors between 8 and $26 \%$. In short, this article shows that there is a balance to be found between the level of dispatchable generation installed, how much can be dispatched due to the merit order effect with vast amounts of zero-marginal cost generation and what is needed to maintain a stable power system. While this analysis does not investigate the risks or challenges listed, we see this as the first step to a technically-complete comparison of decarbonisation scenarios. Through this article we provide a view into the techno-economic aspect of optimally dispatched power systems under different decarbonisation pathways, highlighting concerns related to system operation (reduced capacity factors, inertia levels), economics (shrinking OPEX cost component of total system costs) and emissions reduction (questions over technology choice/reliance/readiness) along the way.

\section{Methods}

\section{Model simulation}

Using PLEXOS Integrated Energy Modelling software (PLEXOS), technical characteristics associated with thermal generation capacity, such as ramp rates or minimum generation levels for example, are all binding while an optimised dispatch of thermal, renewable and storage capacity is created [42-45]. The software is transparent with all equations used in the optimisation available in the form of LP files in each simulation. In this analysis PLEXOS is used to assess the technical feasibility of each scenario in addition to the level of decarbonisation achieved across the region within scope.

While the input data such as wind, solar and demand is hourly in nature, PLEXOS linearly down-scales the data to 5-min resolution. Sub-hourly temporal resolution offers the added benefit of examining the technical ability of generation portfolios to achieve different levels of power output in short temporal timeframes as shown by Deane, Drayton [43]. For example, there is a higher likelihood ramp rates and other technical aspects of thermal generation will bind at 5-min resolution compared hourly dispatch. Deane, Drayton [43] show that increasing temporal resolution increases the accuracy of estimating start cost of thermal power generation capacity.

\section{Input data}

The EC [27, 28] and IEA [29] reports provide information on generation portfolios, electricity demand and observed trends on a supranational and/or national scale, where possible. ENTSO-E [46] and Delucchi, Jacobson [47] provided guidance on VRE installed capacities on a country level for the mitigation scenarios while all other capacities were scaled from the counterfactual. Applying this information facilitated our need to accurately replicate conditions assumed in each report. Calculating the average capacity factor of hydro, nuclear, or biomass for example, allows us to implement constraints in the model to achieve high correlation to each source. As the only two non-EU Member States when these reports were published, no data was available for Switzerland or Norway from the listed sources, thereby power system data was created using the best data available for each country [46-50].

Generation capacities are categorised by class, e.g. hydro, oil, gas, solids, biomass/waste, et cetera. Portfolios are disaggregated into individual power plant types by fuel class and assigned standard technical characteristics as shown in Table 4, an approach previously used by Gaffney, Deane [51]. Thermal generation efficiencies are aligned with International Energy Agency [29]. Hourly generation profiles for wind power and solar photovoltaic were obtained from Gonzalez-Aparicio, Zucker [52] and Pfenninger and Staffell [53] respectively for each country. Normalised hourly generation profiles used in the multi-sample analysis for wind power (onshore and offshore) [54] and solar (photovoltaic [53] from 1985 to 2016 were obtained for each country from the Renewable.ninja [55]. Concentrated solar power with thermal storage was modelled using an approach outlined by [56-58] with a 9-h storage capacity aligning with the latest installations [59] and a $60 \%$ flat heat rate [58]. A solar multiplier of 2 was used, which as the literature $[58,59]$ explains is the ratio between the solar field and the power block output. Other RE was assumed to be primarily ocean energy. Generation profiles and installed capacity distribution among European countries was carried out in alignment with Jacobson, Delucchi [5]. Individual hydro profiles were decomposed from monthly generation constraints from ENTSO-E [60] to weekly and hourly profiles in the optimisation algorithm function within PLEXOS. Pumped hydro energy storage information was sourced from Geth, Brijs [61]. CCS was modelled using the in-build functionality in PLEXOS software to represent the technology - 90\% capture rate is assumed. To represent BECCS assumptions from the '2006 IPCC Guidelines for National Greenhouse Gas Inventories' [62] publication regarding the biogenic carbon content of biomass $\left(100 \mathrm{gCO}_{2} \mathrm{kWh}^{-1}[62,63]\right)$ are applied with a $90 \%$ capture rate applied to assess the 
Table 4 The standardised generation characteristics applied for all 30 countries. Biomass/waste assumes biomass integrated gasification combined cycle (BIGCC) technology is in place, aligning with International Energy Agency [29] assumptions. Ref [1, 29], [2, 5]

\begin{tabular}{|c|c|c|c|c|c|}
\hline Fuel Type & $\begin{array}{l}\text { Capacity } \\
\text { (MW) }\end{array}$ & $\begin{array}{l}\text { Start Cost } \\
(€)\end{array}$ & $\begin{array}{l}\text { Min Stable } \\
\text { Factor } \\
(\%)\end{array}$ & $\begin{array}{l}\text { Ramp Rate } \\
\text { (MW/Min) }\end{array}$ & Efficiency (\%) \\
\hline Biomass/waste & 300 & 10,000 & 30 & 5 & $51 \%(43 \%-$ CCS $)(1)$ \\
\hline Geothermal heat & 70 & 3000 & 40 & 5 & - \\
\hline Hydro (lakes) & 150 & 0 & 0 & 10 & - \\
\hline Hydro (run of river) & 200 & 0 & 0 & 10 & - \\
\hline Natural gas CCGT & 450 & 80,000 & 40 & 20 & $62 \%(54 \%-$ CCS $)(1)$ \\
\hline Natural gas OCGT & 100 & 10,000 & 20 & 50 & $40 \%(1)$ \\
\hline Nuclear & 1200 & 120,000 & 60 & 5 & - \\
\hline Oil & 400 & 75,000 & 40 & 50 & $45 \%(1)$ \\
\hline Solids & 300 & 80,000 & 30 & 5 & $48 \%(41 \%-$ CCS $)(1)$ \\
\hline Pumped hydro & 200 & 0 & 5 & 30 & $80 \%(2)$ \\
\hline Demand response & 100 & - & - & - & $100 \%$ \\
\hline Battery & 100 & - & - & - & $98 \%$ \\
\hline
\end{tabular}

Table 5 Cost assessment specifications. Ref [1]: [73], [2]: [72], [3]: [9], [4, 34]. * A technical lifetime of 80,000 h is assumed for 'low temperature water electrolysis PEM' with a utilisation factor of $90 \%$

\begin{tabular}{|c|c|c|c|c|c|}
\hline Technology & Lifetime & CAPEX & $\mathrm{FO} \& \mathrm{M}$ & VO\&M & Notes \\
\hline Biomass-non-CCS. Ref (1) & 40 & 1700 & 38.4 & 3.26 & CAPEX/FO\&M (€/kW), VO\&M (€/MWh) \\
\hline Biomass-CCS (1) & 40 & 3000 & 61.4 & 5.8 & CAPEX/FO\&M (€/kW), VO\&M (€/MWh) \\
\hline Geothermal heat (1) & 30 & 2613 & 105 & 0.32 & CAPEX/FO\&M (€/kW), VO\&M (€/MWh) \\
\hline Hydro (1) & 55 & 2650 & 16.8 & 0.16 & CAPEX/FO\&M (€/kW), VO\&M (€/MWh) \\
\hline Natural Gas-non-CCS (1) & 30 & 640 & 15 & 2.31 & CAPEX/FO\&M (€/kW), VO\&M (€/MWh) \\
\hline Natural Gas-CCS (1) & 30 & 1500 & 34.3 & 2.78 & CAPEX/FO\&M (€/kW), VO\&M (€/MWh) \\
\hline Nuclear (1) & 60 & 4700 & 105 & 7.8 & CAPEX/FO\&M (€/kW), VO\&M (€/MWh) \\
\hline Oil (1) & 20 & 913 & 17.6 & 0.71 & CAPEX/FO\&M (€/kW), VO\&M (€/MWh) \\
\hline Other RES \& Wave (1) & 80 & 1975 & 23.5 & 0.1 & CAPEX/FO\&M (€/kW), VO\&M (€/MWh) \\
\hline Solar Photovoltaic (2) & 30 & 164 & 0 & 4.2 & CAPEX/FO\&M (€/kW), VO\&M (€/MWh) \\
\hline Concentrated Solar Power (1) & 25 & 3075 & 0 & 0.1 & CAPEX/FO\&M (€/kW), VO\&M (€/MWh) \\
\hline Solids Fired-non-CCS (1) & 40 & 1600 & 25.6 & 2.4 & CAPEX/FO\&M (€/kW), VO\&M (€/MWh) \\
\hline Solids Fired-CCS (1) & 40 & 3200 & 60.6 & 4.04 & CAPEX/FO\&M (€/kW), VO\&M (€/MWh) \\
\hline Wind Onshore (1) & 25 & 943 & 12 & 0.18 & CAPEX/FO\&M (€/kW), VO\&M (€/MWh) \\
\hline Wind Offshore (1) & 25 & 1891 & 28 & 0.39 & CAPEX/FO\&M (€/kW), VO\&M (€/MWh) \\
\hline Battery (2) & 15 & 65 & 0 & 2 & CAPEX/FO\&M (€/kW), VO\&M (€/MWh) \\
\hline Pumped Hydro (1) & 60 & 89 & 20 & 0 & CAPEX (€/MWh stored), FO\&M (€/kW) \\
\hline Transmission - Land (HVAC) (3) & 60 & 866 & 0 & 0 & $(€ / \mathrm{MW} / \mathrm{km})$ \\
\hline Transmission - Subsea (HVDC) (3) & 60 & 1682 & 0 & 0 & $(€ / \mathrm{MW} / \mathrm{km})$ \\
\hline Direct Air Capture (4) & N/A & 199 & 0 & 7.96 & (€/tCO2 captured/year) \\
\hline Power-to-gas: Low temperature water electrolysis PEM (1) & $10^{*}$ & 200 & 10 & 4.2 & CAPEX/FO\&M (€/kW), VO\&M (€/MWh) \\
\hline Carbon Transport \& Storage (1) & N/A & 23 & 1.3 & 1 & (€/tCO2/year) \\
\hline
\end{tabular}


amount of $\mathrm{CO}_{2}$ capture from the process which can offset emissions from other technologies. Generation capacity associated with CCS technology received priority dispatch over thermal power generation capacity. Details of the standardised generation characteristics are outlined in Table 4.

Hourly resolution demand curves were attained from 30-year Member States level historic data from the EC's Joint Research Centre and linearly scaled to the overall demand estimates used for each scenario [64]. Both battery technology and demand response are based on the peak demand of each individual country represented in the model. Both providers of flexibility are sized at 2, 5\% \& $10 \%$ of peak demand in the Reference, Negative Emissions and High VRE scenarios respectively, with $6 \mathrm{~h}$ of storage each. These assumptions are within the range analysed by the European Climate Foundation [65] which investigated flexibility capabilities of up to $20 \%$. This level of flexibility also accounts for future demand profiles being different to past and current profiles. Power-to-gas is included in the High VRE scenario as a means of increasing the level of energy storage in systems with significant levels of variable generation. It is assumed that hydrogen can completely displace natural gas if sufficient volumes are produced via power-to-gas. The ETS carbon price is not applicable to the share of natural gas derived from power-to-gas. Power-to-gas is included in PLEXOS as a demand that purchases low cost power which is converted into gas assuming a conversion efficiency of $60 \%$. The balance between the volume of power purchased and the amount converted back into power must be maintained through post-processing, i.e. multiple simulations and calibration. Kinetic energy (inertia) constants were applied in alignment with Ørum, Kuivaniemi [66].

ENTSO-E's 'Ten Year Network Development Plan' [48] provided the basis for transmission capacity assumptions between countries. The High RES scenario deviates away from this assumption as per Attachment 2, Energy Roadmap 2050 part 2 [28]. Interconnection is limited to net transfers between countries and excludes interregional transfers in line with the EU day-ahead market schedule dispatch clearing algorithm, EUPHEMIA [67, 68]. Malta is the only electrically isolated country modelled.

Coal, oil, natural gas and biomass prices remain consistent across all scenarios at €24, €109, €65 [27] and $€ 31$ [14] per barrel of oil equivalent respectively $\left(\epsilon_{2015}\right)$. Biomass price is based on the average assumed for dedicated perennial biomass crops, forest products and primary forest residues from Tables 11 \& 14, Ruiz, Sgobbi [14]. Emissions Trading Scheme carbon price is assumed $€ 88$ per tonne in the Reference scenario and $€ 264$ per tonne in the Negative Emissions and High RES scenarios, aligning with assumptions made by the European Commission [27]. To contain the level at which
Norwegian hydro capacity could distort cross-border power transfer and consequently, market prices across Europe, the annual capacity factor for hydro was restricted to $50 \%$ of its potential generation capacity which is based on observed system trends over recent years [49, 69-71].

\section{Total system cost assessment}

Total system costs are calculated using data from multiple sources [9, 34, 72, 73]. Technical lifetime, capital expenditures, fixed and variable operation and maintenance costs were all taken from the listed sources using the central option where possible, see Table 5 for specifics. This analysis aligns with its use of the term 'total system costs' with that of the European Commission [40], meaning that carbon-related costs are not accounted for in the calculation since they are not seen as an "extra cost" from a societal perspective. Total system costs are annualised, undiscounted costs where the CAPEX is spread over the technical lifetime of the technology with variable costs also included. $50 \%$ of transmission capacity between the EU-27 plus the United Kingdom connected to Norway and Switzerland is accounted for in cost calculations, representing bilateral arrangements in place to build and maintain interconnection.

\section{Abbreviations \\ CCS: Carbon capture and storage; DAC: Direct air capture; BECCS: Bioenergy carbon capture and storage; VRE: Variable renewable energy; NET: Negative emissions technology; PV: Photovoltaic; CSP: Concentrated solar power; PtG: Power to gas; EC: European Commission; EU: European Union; CO2: Carbon dioxide; TWh: Terawatt hours; GHG: Greenhouse gas; IEA: International Energy Agency; BIGGC: Biomass integrated gasification combined cycle}

\section{Acknowledgements \\ F.G acknowledges that this article contributed to one chapter of his PhD thesis.}

\section{Authors' contributions}

F.G. developed the power system model which was validated by G.D. G.D. also provided cloud computing services to expediate the simulation process. F.G. wrote this chapter in its entirety while B. O'G., P.D., G. D and J.G. provided guidance and reviewed drafts. All authors have read and approved the final manuscript.

\section{Funding \\ F.G. acknowledges the support provided by Bord Gáis Energy. P.D. and B.O'G. were supported by the Science Foundation Ireland (SFI) MaREI Centre (12/ RC/2302_P2). JG is supported by a research grant from Science Foundation Ireland (SFI) and the National Natural Science Foundation of China (NSFC) under the SFI-NSFC Partnership Programme, Grant Number 17/NSFC/ 5181. The respective funding bodies did not play any role in the design of the study or the collection, analysis, interpretation of data or in writing the manuscript.}

\section{Availability of data and materials}

Please contact corresponding author for data requests.

Competing interests

Not applicable. 


\section{Author details}

'MaREl Centre, Environmental Research Institute, University College Cork, Cork, Ireland. ${ }^{2}$ School of Engineering, University College Cork, Cork, Ireland. ${ }^{3}$ Energy Exemplar, Adelaide, Australia.

\section{Received: 9 August 2019 Accepted: 14 April 2020 \\ Published online: 13 May 2020}

\section{References}

1. UNFCCC. Adoption of the Paris Agreement. Report No FCCC/CP/2015/L9/ Rev1. 2015.

2. Creutzig F, Breyer C, Hilaire J, Minx J, Peters GP, Socolow R. The mutual dependence of negative emission technologies and energy systems. Energy Environ Sci. 2019;12(6):1805-17.

3. Teske S. Achieving the Paris climate agreement goals: springer; 2019

4. IPCC. Global Warming of 1.5C. Special Report: An IPCC special report on the impacts of global warming of 1.5C above pre-industrial levels and related global greenhouse gas emission pathways, in the context of strengthening the global response to the threat of climate change, sustainable development, and efforts to eradicate poverty. Republic of Korea: IPCC; 2018. Report No.: 9291691437.

5. Jacobson MZ, Delucchi MA, Cameron MA, Mathiesen BV. Matching demand with supply at low cost in 139 countries among 20 world regions with $100 \%$ intermittent wind, water, and sunlight (WWS) for all purposes. Renew Energy. 2018;123:236-48.

6. Pursiheimo $\mathrm{E}$, Holttinen $\mathrm{H}$, Koljonen $\mathrm{T}$. Inter-sectoral effects of high renewable energy share in global energy system. Renew Energy. 2019;136: 1119-29.

7. Bogdanov D, Farfan J, Sadovskaia K, Aghahosseini A, Child M, Gulagi A, et al. Radical transformation pathway towards sustainable electricity via evolutionary steps. Nat Commun. 2019;10(1):1077.

8. Connolly D, Lund H, Mathiesen BV. Smart energy Europe: the technical and economic impact of one potential 100\% renewable energy scenario for the European Union. Renew Sust Energ Rev. 2016;60:1634-53.

9. Zappa W, Junginger M, van den Broek M. Is a 100\% renewable European power system feasible by 2050? Appl Energy. 2019;233:1027-50.

10. Child M, Kemfert C, Bogdanov D, Breyer C. Flexible electricity generation, grid exchange and storage for the transition to a $100 \%$ renewable energy system in Europe. Renew Energy. 2019;139:80-101.

11. Bussar C, Stöcker P, Cai Z, Moraes L Jr, Magnor D, Wiernes P, et al. Largescale integration of renewable energies and impact on storage demand in a European renewable power system of 2050-sensitivity study. J Energy Storage. 2016;6:1-10.

12. Jägemann C, Fürsch $M$, Hagspiel S, Nagl S. Decarbonizing Europe's power sector by 2050 - analyzing the economic implications of alternative decarbonization pathways. Energy Econ. 2013:40:622-36.

13. Trutnevyte E. Does cost optimization approximate the real-world energy transition? Energy. 2016;106:182-93.

14. Ruiz, Pablo, Alessandra Sgobbi, Wouter Nijs, Christian Thiel, Francesco Dalla Longa, Tom Kober, Berien Elbersen, and Geerten Hengeveld. "The JRC-EUTIMES model. Bioenergy potentials for EU and neighbouring countries." JRC Science for Policy Report, European Commission. 2015.

15. Vangkilde-Pedersen T, Anthonsen KL, Smith N, Kirk K, van der Meer B, Le Gallo $Y$, et al. Assessing European capacity for geological storage of carbon dioxide-the EU GeoCapacity project. Energy Procedia. 2009;1 (1):2663-70.

16. Dooley JJ. Estimating the supply and demand for deep geologic $\mathrm{CO} 2$ storage capacity over the course of the 21st century: a meta-analysis of the literature. Energy Procedia. 2013;37:5141-50.

17. Lewis D, Bentham M, Cleary T, Vernon R, O'Neill N, Kirk K, et al. Assessment of the potential for geological storage of carbon dioxide in Ireland and Northern Ireland. Energy Procedia. 2009;1(1):2655-62.

18. Kotzur L, Markewitz P, Robinius M, Stolten D. Time series aggregation for energy system design: Modeling seasonal storage. Appl Energy. 2018;213: $123-35$

19. Jacobson MZ, Delucchi MA, Bazouin G, Bauer ZA, Heavey CC, Fisher E, et al. 100\% clean and renewable wind, water, and sunlight (WWS) all-sector energy roadmaps for the 50 United States. Energy Environ Sci. 2015;8(7): 2093-117.

20. Clack CT, Qvist SA, Apt J, Bazilian M, Brandt AR, Caldeira K, et al. Evaluation of a proposal for reliable low-cost grid power with $100 \%$ wind, water, and solar. Proc Natl Acad Sci. 2017;114(26):6722-7.
21. Pfenninger $S$. Energy scientists must show their workings. Nature News. 2017:542(7642):393.

22. Downing SM. Reliability: on the reproducibility of assessment data. Med Educ. 2004;38(9):1006-12.

23. Begley CG, Ellis LM. Drug development: raise standards for preclinical cancer research. Nature. 2012:483(7391):531.

24. Pfenninger S, DeCarolis J, Hirth L, Quoilin S, Staffell I. The importance of open data and software: is energy research lagging behind? Energy Policy. 2017;101:211-5.

25. DeCarolis JF, Hunter K, Sreepathi S. The case for repeatable analysis with energy economy optimization models. Energy Econ. 2012;34(6):1845-53.

26. Nature. Journals unite for reproducibility. Nature. 2014;515:7.

27. Capros P, De Vita A, Tasios N, Siskos P, Kannavou M, Petropoulos A, et al. EU reference scenario 2016-energy, transport and GHG emissions trends to 2050. 2016.

28. European Commission. Energy Roadmap 2050. Brussels, XXX COM (2011). 2011;885(2)

29. International Energy Agency. Energy technology perspectives 2017: Catalysing energy technology transformations. Paris: IEA; 2017.

30. Collins S, Deane P, Ó Gallachóir B, Pfenninger S, Staffell I. Impacts of Interannual Wind and Solar Variations on the European Power System. Joule; 2018.

31. Smith P, Davis SJ, Creutzig F, Fuss S, Minx J, Gabrielle B, et al. Biophysical and economic limits to negative CO 2 emissions. Nat Clim Chang. 2016;6(1):42.

32. Climeworks A. Capturing CO2 from the air: our technology; 2018.

33. Realmonte G, Drouet L, Gambhir A, Glynn J, Hawkes A, Köberle AC, et al. An inter-model assessment of the role of direct air capture in deep mitigation pathways. Nat Commun. 2019;10(1):3277.

34. Fasihi M, Efimova O, Breyer C. Techno-economic assessment of $\mathrm{CO} 2$ direct air capture plants. J Clean Prod. 2019;224:957-80.

35. Connolly D, Lund H, Mathiesen BV, Werner S, Möller B, Persson U, et al. Heat roadmap Europe: combining district heating with heat savings to decarbonise the EU energy system. Energy Policy. 2014;65:475-89.

36. Ørum E, Haarla L, Kuivaniemi M, Laasonen M, Jerko A, Stenklov I, et al. Future system inertia 2. Brussles; 2015

37. Daly P, Flynn D, Cunniffe N. Inertia considerations within unit commitment and economic dispatch for systems with high non-synchronous penetrations. In 2015 IEEE Eindhoven PowerTech. IEEE; 2015. p. 1-6.

38. Future system inertia [Internet]. ENTSO-E. 2016 [cited January 5 2017]. Available from: http://tyndp.entsoe.eu/reference/\#downloads.

39. Vivid Economics, Imperial College London. Thermal generation and electricity system reliability. Report prepared for NRDC; 2018.

40. European Commission. A policy framework for climate and energy in the period from 2020 to 2030. COM, vol. 2014; 2014. p. 15.

41. Zakkour P, Kemper J, Dixon T. Incentivising and accounting for negative emission technologies. Energy Procedia. 2014;63:6824-33.

42. Deane JP, Ó Ciaráin M, BP ÓG. An integrated gas and electricity model of the EU energy system to examine supply interruptions. Appl Energy. 2017; 193:479-90.

43. Deane P, Drayton G, Ó Gallachóir B. The impact of sub-hourly modelling in power systems with significant levels of renewable generation. Appl Energy. 2014;113:152-8.

44. Drayton G, McCoy M, Pereira M, Cazalet E, Johannis M, Phillips D. Transmission expansion planning in the Western interconnection-the planning process and the analytical tools that will be needed to do the job. In IEEE PES Power Systems Conference and Exposition. IEEE; 2004. p. 155661.

45. Welsch M, Deane P, Howells M, Ó Gallachóir B, Rogan F, Bazilian M, et al. Incorporating flexibility requirements into long-term energy system models - A case study on high levels of renewable electricity penetration in Ireland. Appl Energy. 2014;135:600-15.

46. TYNDP 2018 Market Modeling Data [Internet]. ENTSO-E. 2018 [cited April 2018]. Available from: http://tyndp.entsoe.eu/maps-data/.

47. Delucchi MA, Jacobson MZ, Bauer ZAF, Goodman S, Chapman W. Spreadsheets for 139 -country $100 \%$ wind, water, and solar roadmaps; 2016.

48. TYNDP 2016 Market Modeling Data [Internet]. ENTSO-E. 2016 [cited January 5 2017]. Available from: http://tyndp.entsoe.eu/reference/\#downloads.

49. Swiss Federal Office of Energy. Electricity Statistics: Swiss Federal Administration; 2017 [Available from: http://www.bfe.admin.ch/themen/ 00526/00541/00542/00630/index.html?lang=en\&dossier_id=00769. 
50. Albrecht M, Nilsson M, Åkerman J. Nordic power road map 2050: Strategic choices towards carbon neutrality. D4. 2. R Policy and Institutional Review Electric Vehicles (EV). 2012.

51. Gaffney F, Deane J, Collins S, Gallachóir BÓ. Consumption-based approach to RES-E quantification: insights from a pan-European case study. Energy Policy. 2018;112:291-300.

52. Aparicio G, Zucker A, Careri F, Monforti F, Huld F, Badger J. EMHIRES dataset. Part I: Wind power generation European Meteorological derived HIgh resolution RES generation time series for present and future scenarios. EUR 28171 EN. 2016.

53. Pfenninger S, Staffell I. Long-term patterns of European PV output using 30 years of validated hourly reanalysis and satellite data. Energy. 2016;114: 1251-65.

54. Staffell I, Pfenninger S. Using bias-corrected reanalysis to simulate current and future wind power output. Energy. 2016;114:1224-39.

55. Pfenninger S, Staffell I. Renewable.ninja 2016 [Available from: https://www. renewables.ninja/.

56. Denholm P, Hummon M. Simulating the value of concentrating solar power with thermal energy storage in a production cost model; 2012.

57. Denholm, P. and Mehos, M., 2014. Enabling greater penetration of solar power via the use of CSP with thermal energy storage. Solar Energy: Application, Economics, and Public Perception, 99.

58. Denholm P, Wan Y-H, Hummon M, Mehos M. Analysis of concentrating solar power with thermal energy storage in a California 33\% renewable scenario. Golden: National Renewable Energy Laboratory (NREL); 2013.

59. National Renewable Energy Laboratory. Concentrating solar power projects 2017 2017. [updated 15. Available from: https://www.nrel.gov/csp/ solarpaces/index.cfm.

60. ENTSO-E. Consumption Data Brussels: ENTSO-E; 2012 [Available from: https://www.entsoe.eu/data/data-portal/consumption/Pages/default.aspx.

61. Geth F, Brijs T, Kathan J, Driesen J, Belmans R. An overview of large-scale stationary electricity storage plants in Europe: current status and new developments. Renew Sust Energ Rev. 2015;52:1212-27.

62. Gómez DR, John D. Watterson, Branca B. Americano, Chia Ha, Gregg Marland, Emmanuel Matsika, et al. IPCC guidelines for national greenhouse gas inventories: energy. IPCC; 2006

63. Anderson K, Peters G. The trouble with negative emissions. Science. 2016; 354(6309):182-3.

64. European Commission. Strategic Energy Technologies Information System Brussels: European Commission; 2017 [Available from: https:/setis.ec.europa.eu/.

65. European Climate Fund. Roadmap 2050: a practical guide to a prosperous, low carbon Europe. Brussels: ECF; 2010.

66. Ørum E, Kuivaniemi M, Laasonen M, Bruseth Al, Jansson EA, Danell A, et al. Future system inertia. Brussles: ENTSOE; 2015.

67. N-SIDE. EUPHEMIA Brussels [Available from: http://energy.n-side.com/dayahead/.

68. EPEX Spot. EUPHEMIA: description and functioning. Brussels: EPEX Spot; 2016

69. Eurostat. European Statistics 2016 [Available from: http://ec.europa.eu/ eurostat/web/energy/data/database.

70. ENTSO-E. Exchange Data 2016 [Available from: https://www.entsoe.eu/data/ data-portal/exchange/Pages/default.aspx.

71. ENTSO-E. Statistical Factsheet 2017 [Available from: https:/www.entsoe.eu/ publications/statistics/statistical-factsheet/Pages/defaultaspx.

72. Vartiainen E, Masson G, Breyer C, Moser D, Román ME. Impact of weighted average cost of capital, capital expenditure, and other parameters on future utility-scale PV levelised cost of electricity. Progress in Photovoltaics: Research and Applications; 2019.

73. De Vita A, Kielichowska I, Mandatowa P, Capros P, Dimopoulou E, Evangelopoulou S, et al. Technology pathways in decarbonisation scenarios. Brussels: Tractebel, Ecofys, E3-Modelling; 2018.

\section{Publisher's Note}

Springer Nature remains neutral with regard to jurisdictional claims in published maps and institutional affiliations.

Ready to submit your research? Choose BMC and benefit from:

- fast, convenient online submission

- thorough peer review by experienced researchers in your field

- rapid publication on acceptance

- support for research data, including large and complex data types

- gold Open Access which fosters wider collaboration and increased citations

- maximum visibility for your research: over $100 \mathrm{M}$ website views per year

At BMC, research is always in progress.

Learn more biomedcentral.com/submissions 